\title{
Electrochemical Analysis of Synthetized Iridium Nanoparticles for Oxygen Evolution Reaction in Acid Medium
}

\author{
P. Lettenmeier ${ }^{\mathrm{a}}$, J. Majchel ${ }^{\mathrm{a}}$, L. Wang ${ }^{\mathrm{a}}$, A. S. Gago ${ }^{\mathrm{a}, 1}$, K. A. Friedrich ${ }^{\mathrm{a}, \mathrm{b}}$ \\ a Institute of Engineering Thermodynamics, German Aerospace Center, Pfaffenwaldring \\ 38-40, Stuttgart, 70569, Germany \\ ${ }^{\mathrm{b}}$ Institute of Energy Storage, University of Stuttgart, Stuttgart, 70550, Germany
}

The anode side catalyst is one of the key parts for sustainable hydrogen production via proton exchange membrane (PEM) electrolysis. An optimized synthesis of the oxygen evolution reaction (OER) catalysts may lead to a cost efficient production, promoting the commercialization of new catalyst materials. This work compares the electrochemical characteristics of Ir nanoparticles synthetized in different purities of ethanol and deionized (DI) water as solvents. The use of cetyltrimethyl ammonium bromide (CTAB) as a surfactant is discussed as well. In general, the absence of the surfactant and use of either low ethanol purity or water is detrimental for electrocatalytic properties of the materials. Changes in the Tafel slope are observed, while the analysis of the specific exchange current can be misleading. The active sites from the $\operatorname{Ir}^{\mathrm{III}} / \mathrm{Ir}^{\mathrm{IV}}$ oxidation peak do not correlate exactly with the OER activities, while the capacitive current provides more meaningful information.

\section{Introduction}

The third Conference of the Parties 1998 (COP3) with the resolution of the Kyoto protocol (1) was the first tangible result on the way to a sustainable energy and climate policy. Finally this year, the parties agreed to limit the global climate change and the average rising temperature by $2{ }^{\circ} \mathrm{C}(2)$. During the last decade the installed renewable wind and solar power increased significantly which leads to a volatile power supply system. An efficient use of these systems requires an upgrade in the electricity grid or the use of energy storage systems to keep the supply safe and reliable (3). One way to store renewable energy is the conversion by storing it chemically and in particular the conversion via electrolysis of water to hydrogen. Proton exchange membrane (PEM) water electrolysis is a promising technology to produce green high purity hydrogen from renewable electricity. Electrolyzers are modular devices and can be designed as centralized or distributed plants, enabling their numerous application from refueling to bulk electricity storage (4). At high production rates, i.e. systems in the mega- or gigawatt range, the availability of iridium as the state of the art catalyst may become a serious issue (5). For this reason, the amount of catalyst loading in the membrane electrode assembly (MEA) plays an important role. Consequently, there is an increased interest from the scientific community and industry in optimizing the electrochemical activity of

${ }^{1}$ Corresponding author: Tel.: +49 711 6862-8090, fax: +49 711 6862-747, e-mail address: aldo.gago@dlr.de (A.S. Gago). 
iridium by increasing the active surface area (6-8), changing the crystalline structure $(9,10)$ or using support materials $(11-13)$. For an industrial production of the catalyst, the costs of the synthesis procedure and in particular the amount and purity of the chemicals, is relevant. We showed in our previous work that the $\mathrm{IrO}_{\mathrm{x}}$-Ir catalyst can be synthesized by following a straightforward procedure by reducing surfactant-stabilized iridium ions in dry ethanol. However, high purity ethanol is costly and the higher the purity, the more expensive it is. Moreover, using water and avoiding the surfactant at all would be preferable for a production of the catalyst at the industrial scale. In this work, we investigated the impact of the ethanol purity and amount of chemicals used for the synthesis of Ir nanoparticles. The influence of the synthesis conditions on the OER activity and the use of common electrochemical evaluation procedures are discussed.

\section{Experimental}

\section{Catalyst synthesis}

A wet-chemical synthesis method is selected for the synthesis of the catalyst nanoparticles (8). In short, $5.265 \mathrm{~g}$ of cetyltrimethyl ammonium bromide (CTAB), which reduces the surface tension of the liquid phase, thereby increasing the dispersion of particles, is dissolved in $540 \mathrm{ml}$ of ethanol (EtOH). In a parallel step, $448 \mathrm{mg}$ of the precursor iridium (III) chloride $\left(\mathrm{IrCl}_{3}\right)$ is dissolved in $225 \mathrm{ml}$ of EtOH using ultrasonic bath for about 10 minutes. Contact with the ambient air is avoided as much as possible, to prevent contamination of the high purity ethanol with humidity. Therefore, all used round-bottomed flasks are flushed with an inert gas such as argon or nitrogen and sealed with a rubber stopper, before the ethanol is added with a syringe. Both solutions are added into a three-neck flask and stirred for 30 minutes using a magnetic stirrer at 480 rpm. Subsequently, $684 \mathrm{mg}$ of sodium borohydride $\left(\mathrm{NaBH}_{4}\right)$ is dissolved in $90 \mathrm{ml}$ of ethanol with the help of an ultrasonic bath for 10 minutes. The dissolved reducing agent is added afterwards with approximately $2-3 \mathrm{ml} \mathrm{min}^{-1}$, while increasing the agitation to $600 \mathrm{rpm}$ and under inert gas atmosphere for about $12 \mathrm{~h}$. The synthesized suspension of Ir nanoparticles (Ir-nano) is separated by the use of a centrifuge for 4 minutes at 7,600 rpm. As cleaning procedure, the powder was dissolved in EtOH and separated by centrifuge again for removing the surfactant. That is carried out 4 times in $\mathrm{EtOH}$ and 4 times in deionized (DI) water. Finally, the wet powder is dried in a furnace at a temperature of $40{ }^{\circ} \mathrm{C}$.

Ethanol of different purities was used for the synthesis to reduce cost and determine its influence in the material properties. The configuration for the different synthesis is summarized in Table 1. Furthermore, the influence of the CTAB and the use of DI water instead of $\mathrm{EtOH}$ are investigated as well for additional cost reduction. 
TABLE 1. Arrangement of synthesis of Ir nanoparticles.

\begin{tabular}{ccc}
\hline Catalyst name & Solvent & Ir precursor \\
\hline Ir-nano 99.8 & $\geq 99.8 \%$ pure $\mathrm{EtOH}^{\mathrm{a}}$ & $\mathrm{IrCl}_{3}{ }^{\mathrm{b}}$ \\
Ir-nano 99.5 & $\geq 99.5 \%$ pure $\mathrm{EtOH}^{\mathrm{c}}$ & $\mathrm{IrCl}_{3}$ \\
Ir-nano 99.5\CTAB & $\geq 99.5 \%$ pure EtOH, without $\mathrm{CTAB}^{\mathrm{d}}$ & $\mathrm{IrCl}_{3}$ \\
Ir-nano 91.5 & $\geq 91.5 \%$ pure EtOH & $\mathrm{IrCl}_{3}$ \\
Ir-nano $\mathrm{H}_{2} \mathrm{O}$ & DI water $\mathrm{H}_{2} \mathrm{O}^{\mathrm{f}}$ & $\mathrm{IrCl}_{3}$ \\
\hline
\end{tabular}

${ }^{a}$ Ethanol absolute, water free (VWR Chemicals, Product-No.: 83672), Purity $\geq 99,8 \%$

${ }^{\mathrm{b}}$ Iridium(III)-chloride, dried, min. $62 \% \operatorname{Ir}$ (Alfa Aesar, Product-No.:12158)

${ }^{c}$ Ethanol absolute (VWR Chemicals, Product-No.: 20816), Purity $\geq 99,5 \%$

${ }^{\mathrm{d}}$ Cetyltrimethyl ammonium bromide (VWR Chemicals, Product-No.: 22610.132)

${ }^{\mathrm{e}}$ Ethanol 99\% (VWR Chemicals, Product-No.: 84835), Purity $\geq 91,5 \%$

${ }^{\mathrm{f}}$ Water (VWR Chemicals, Product-No.: 90200 ), conductivity $\leq 1,1 \mu \mathrm{S} \cdot \mathrm{cm}^{-1}$

\section{Electrode preparation}

A three-electrode assembly was used for the electrochemical characterization of the catalyst powder. A rotating disc electrode (RDE, Pine Research Instrumentation) served as working electrode. A platinum wire rod was used as a counter electrode and a reversible hydrogen electrode (RHE, Hydroflex of Gaskatel) was used as reference electrode. The OER measurements were performed with a potentiostat/galvanostat (PGSTAT12 Metrohm Autolab) and a second potentiostat (IM6 of Zahner-Elektrik) was used for determining the ohmic drop through impedance spectroscopy (EIS). The catalyst ink is produced by dispersing $10 \mathrm{mg}$ of the cleaned synthesized material in $8.3 \mathrm{ml}$ ultrapure water (Water, ultrapure, HPLC Grade (Alfa Aesar, Produkt-Nr.: 22934)) and 0.04 $\mathrm{ml}$ of $5 \mathrm{w} \%$ Nafion resin solution (Sigma Aldrich, Produkt-Nr.: SAFA274704). The catalyst ink is drop-casted on the glassy carbon disc, which is mounted on the shaft of the rotator and the rotation speed is adjusted by means of a control device. The electrode was polished until mirror-finishing before depositing $10 \mu \mathrm{l}$ of the ink on the electrode by use of a pipette. The coating, which contains $6.1 \times 10^{-5} \mathrm{~g}_{\mathrm{Ir}} \mathrm{cm}^{-2}$, is dried in Ar atmosphere before immersion into the cell. Ir-black (Ir-black UC, Umicore) is used as commercial reference and benchmark catalyst (14).

\section{$\underline{\text { Electrochemical measurements }}$}

A solution of $0.5 \mathrm{M}$ sulfuric acid $\left(\mathrm{H}_{2} \mathrm{SO}_{4}\right)$ was used as electrolyte. It was flushed for at least 10 minutes with inert gas before the ink coated-RDE is immersed into the cell and connected to the potentiostat. During measurements, the gas supply is not interrupted. Before each OER measurement, EIS was performed to determine the ohmic resistance of the electrolyte. The rotation speed of the RDE was adjusted to 2,300 rpm for all cyclic voltammetry $(\mathrm{CV})$ measurements following the protocol of Table 2. CV1 is performed to determine the OER activity between 1 and $1.6 \mathrm{~V} v s$. RHE. CV2 was performed afterwards to clean the surface, and CV3 to calculate the turn-over frequency from the $\mathrm{Ir}^{3+} / \mathrm{Ir}^{4+}$ redox peak and for material characterization. All measurements were $\mathrm{iR}$ and capacitance corrected. 
TABLE 2. Protocol of electrochemical characterization

\begin{tabular}{cccc}
\hline CV & Potential & Scanning rate & Amount of cycles \\
\hline 1 & $1.00 \mathrm{~V}-1.60 \mathrm{~V}$ & $5 \mathrm{mV} \mathrm{s}^{-1}$ & 3 \\
2 & $0.05 \mathrm{~V}-1.50 \mathrm{~V}$ & $500 \mathrm{mV} \mathrm{s}^{-1}$ & 50 \\
3 & $0.40 \mathrm{~V}-1.40 \mathrm{~V}$ & $20 \mathrm{mV} \mathrm{s}^{-1}$ & 3 \\
\hline
\end{tabular}

\section{Discussion of results}

\section{$\underline{\text { OER Activity }}$}

The synthetized materials with different purities of EtOH, in water and without CTAB were thoroughly characterized in the electrochemical setup. Figure 1a shows the OER performance of all synthesized materials. As expected the catalyst synthetized in $\geq 99.8 \%$ pure EtOH (Ir-nano 99.8) shows slightly higher OER activity than $\geq 99.5 \%$ pure $\mathrm{EtOH}$ (Ir-nano 99.5). Taking into account the error bars generated from multiple measurements, the performance difference of those two catalysts can be considered negligible. The influence of the surfactant CTAB can be distinguished by comparing Irnano 99.5 (with surfactant) with Ir-nano 99.5 loss of efficiency can be observed for 99.5\CTAB and the performance is in the same range as Ir-black. Reducing further the solvent purity down to $100 \%$ water (Ir-nano $\mathrm{H}_{2} \mathrm{O}$ ), led to a significant loss of OER activity.
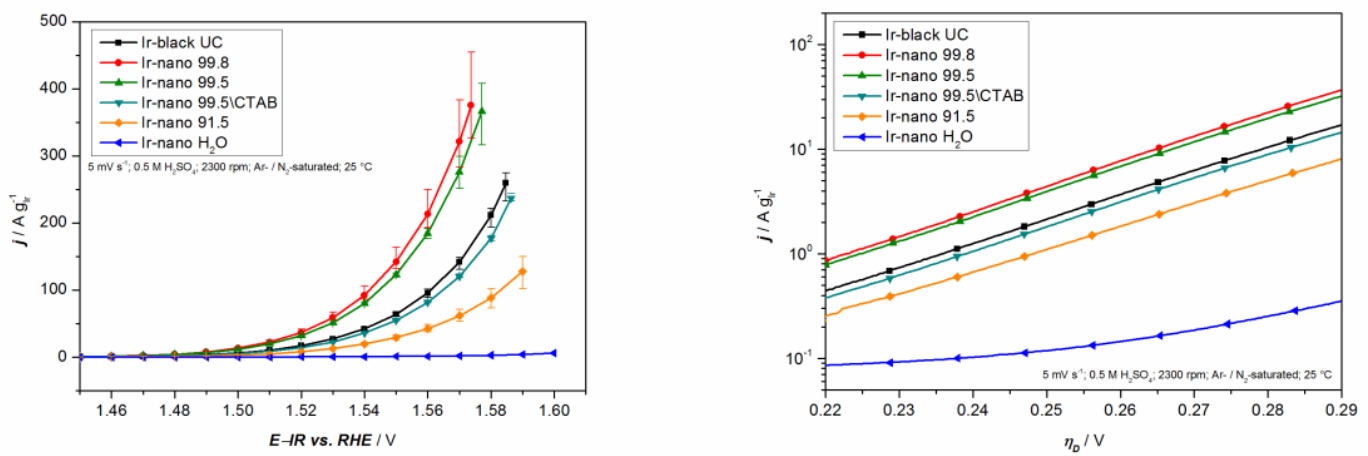

Figure 1. a) OER activity and b) Tafel slopes for Ir-black UC; Ir-nano 99.8; Ir-nano 99.5; Ir-nano 99.5\CTAB; Ir-nano 91.5 and Ir-nano $\mathrm{H}_{2} \mathrm{O}$. The scanning rate, temperature and rotation speed are $5 \mathrm{mV} \mathrm{s}^{-1}, 25^{\circ} \mathrm{C}$, and $2300 \mathrm{rpm}$, respectively. The measurements were performed in $0.5 \mathrm{M} \mathrm{H}_{2} \mathrm{SO}_{4}$ and Ar-saturated solution.

Figure $1 \mathrm{~b}$ presents the Tafel slopes of all the measured catalysts. The activation current density $\left(j_{A}\right)$ and overpotential $\left(\eta_{A}\right)$ were calculated as follow:

$$
\begin{aligned}
\mathrm{j}_{\mathrm{A}} & =\log \mathrm{j}_{0}+(\alpha \mathrm{zF} / 2.303 \mathrm{RT}) * \eta_{\mathrm{A}} \\
\eta_{\mathrm{A}} & =(\mathrm{RT} / \alpha \mathrm{zF}) * \ln \left(\mathrm{j} / \mathrm{j}_{0}\right)
\end{aligned}
$$

where $\mathrm{R}$ is the ideal gas constant, $\mathrm{T}$ the temperature, $\mathrm{z}$ the number of the involved electrons for water splitting, $\alpha$ the transfer coefficient, $\mathrm{j}_{0}$ the exchange current density, and $\mathrm{F}$ is the Faraday constant $\left(96485 \mathrm{C} \mathrm{mol}^{-1}\right)$. The Tafel equation (equation 1) is useful 
for determining $\alpha$ and $\mathrm{j}_{0}$, which are the most important parameters of the Butler-Volmer equation (equation 2). Table 3 summarizes all electrochemical parameters extracted from figure $1 \mathrm{a}$ and $\mathrm{b}$. The Tafel slope was fitted for all catalysts with $\mathrm{EtOH}$ at over potentials between 230 and $260 \mathrm{mV}$ and for the one synthetized in $\mathrm{H}_{2} \mathrm{O}$ between $300 \mathrm{mV}$ and 330 $\mathrm{mV}$ respectively. It is worthwhile noting that the graphical analysis of the measured CVs, which are all capacity and $\mathrm{iR}$ corrected, is highly sensible and small differences in the Tafel slopes may result in unexpected exchange current densities after extrapolation to zero overpotential. Changes in the intrinsic activity and the corresponding specific exchange current can cause the decrease in the OER activity, since these properties are not expected to change by using different solvents. The exchange current density and $\alpha$ can be calculated by fixing the Tafel slope to a reasonable value (e.g. $40 \mathrm{mV} \mathrm{dec}{ }^{-1}$ ), if modelling data are required for comparing activities at reasonable potentials such as 1.48 $\mathrm{V}, 1.51 \mathrm{~V}$ or $1.56 \mathrm{~V}$ as it is customary in the literature $(8,11-13,15,16)$. In case of the Irnano $\mathrm{H}_{2} \mathrm{O}$ the electrochemical parameters are not comparable anymore by using the Tafel equation combined with the assumption that the material properties do not differ from the other catalyst materials.

TABLE 3. Electrochemical parameters (Note that the authors consider the $\mathrm{j}_{0}$ to inherently unreliable)

\begin{tabular}{|c|c|c|c|c|c|c|c|}
\hline Ink & 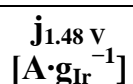 & $\begin{array}{c}\mathbf{j}_{1.56 \mathrm{~V}} \\
{\left[\mathbf{A} \cdot \mathbf{g}_{\mathrm{Ir}}{ }^{-1}\right]}\end{array}$ & $\begin{array}{c}b \\
{\left[\mathrm{mV} \cdot \mathrm{dec}^{-1}\right]}\end{array}$ & $\alpha[-]$ & $\begin{array}{c}\mathbf{j}_{0} \cdot \mathbf{1 0}^{-6} \\
{\left[\mathbf{A} \cdot \mathbf{g}_{\text {Ir }}\right]}\end{array}$ & $\begin{array}{l}\mathbf{E}_{\text {on }} \\
{[\mathbf{V}]}\end{array}$ & $\begin{array}{l}\mathbf{j}_{\text {cap }} \cdot 10^{-1} \\
{\left[\mathrm{~A}^{-1} \cdot \mathrm{g}_{\mathrm{Ir}}{ }^{-1}\right]}\end{array}$ \\
\hline Ir-black UC & 2.2 & 95 & 42.9 & 0.69 & 3.16 & 1.443 & 3.55 \\
\hline Ir-nano 99,8 & 4.4 & 213 & 41.2 & 0.72 & 3.79 & 1.438 & 6.99 \\
\hline Ir-nano 99,5 & 3.9 & 184 & 41.7 & 0.71 & 3.93 & 1.439 & 7.67 \\
\hline $\begin{array}{c}\text { Ir-nano } \\
\text { 99,5\CTAB }\end{array}$ & 1.8 & 81 & 42.7 & 0.69 & 2.57 & 1.433 & 2.99 \\
\hline Ir-nano 91,5 & 1.1 & 43 & 46.4 & 0.64 & 4.48 & 1.434 & 2.12 \\
\hline Ir-nano $\mathrm{H}_{2} \mathrm{O}$ & 0.1 & 1.5 & 63.8 & 0.46 & 9.92 & 1.477 & - \\
\hline
\end{tabular}

Figure 2 shows the forward linear voltammetry scan between 1.2 and $1.6 \mathrm{~V}$ vs. RHE (without capacitance correction). This plot was used to determine the onset potentials $\mathrm{E}_{\mathrm{on}}$, which are also summarized in Table 3 . No significant differences can be observed in the $\mathrm{E}_{\text {on }}$ for the ethanol synthesized catalysts, while for Ir-nano $\mathrm{H}_{2} \mathrm{O}$ the onset potential shifts largely to higher potentials. Moreover, the Tafel slope for this material is around $60 \mathrm{mV}$ $\operatorname{dec}^{-1}$ which indicates, if not a different material, at least a different rate determining step for OER (17). Due to the low activity of the catalyst synthesized with water as a solvent, Ir-nano $\mathrm{H}_{2} \mathrm{O}$ will no longer be considered for further discussion. 


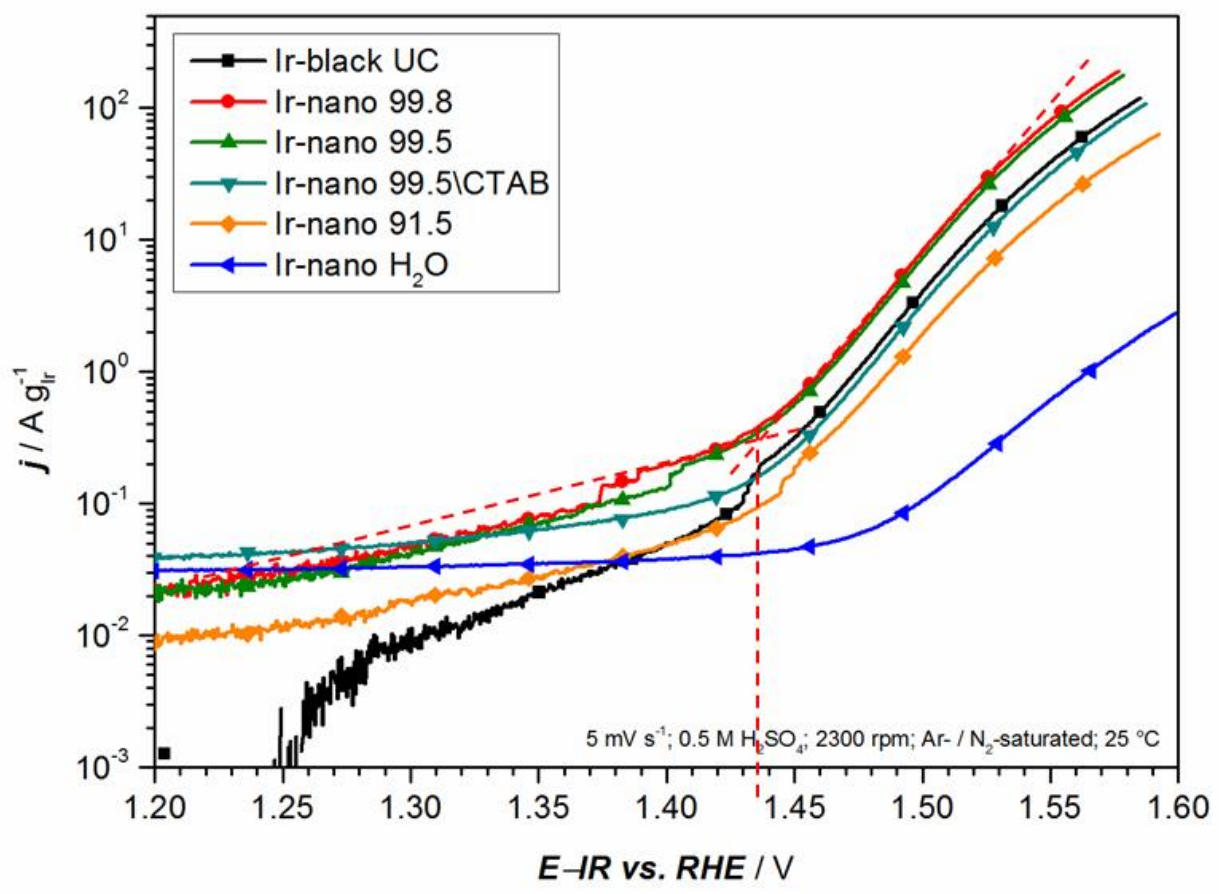

Figure 2. Tafel slopes from the forward linear scan of all materials measured in the same conditions as for Figure 1a but without capacity correction.

Figure 3 shows CVs of the different catalysts between 0.4 and $1.4 \mathrm{~V}$ vs. RHE. Interesting is the large redox peak from $\mathrm{Ir}^{\mathrm{III}}$ to $\mathrm{Ir}^{\mathrm{IV}}$ of Ir-black. The synthesized catalysts and reference catalyst are highly metallic with a thin oxide/hydroxide layer on the surface (8). This is the case for the most active metallic Ir-based catalysts, published recently $(8,10,15,18)$. Ambient pressure XPS reports the existence of $\operatorname{Ir}^{\mathrm{V}}(18)$, which is reduced to Ir III after oxygen evolution (16). In this context, the analysis of the anodic charge of the capacity corrected $\operatorname{Ir}^{\mathrm{III}}$ to $\operatorname{Ir}^{\mathrm{IV}}$ oxidation peak $(8,15,19)$ may be a suitable way for estimation of the number of active size. 


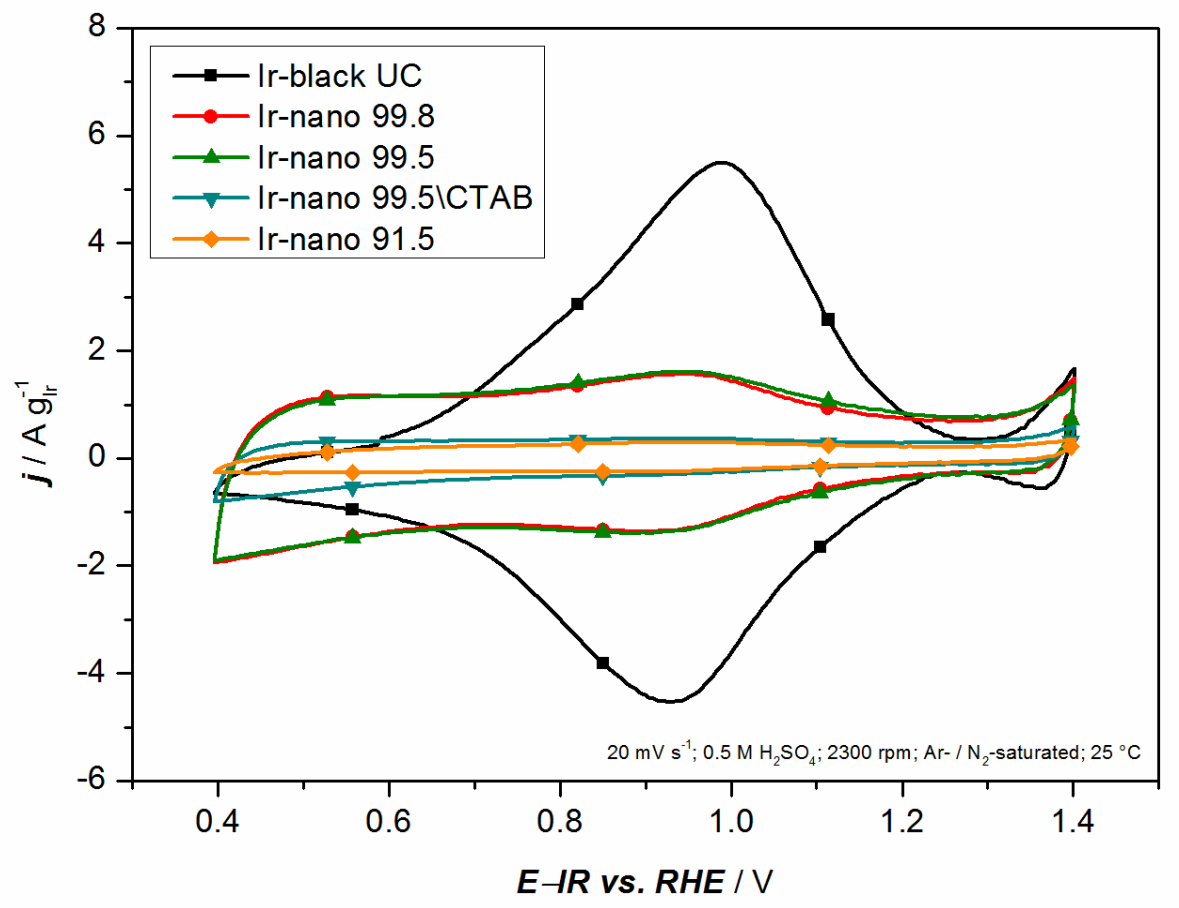

Figure 3. $\mathrm{CV}$ of all materials synthesized with EtOH between 0.4 and $1.4 \mathrm{~V}$ without rotation and a scanning rate of $20 \mathrm{mV} \mathrm{s}^{-1}$. The measurements were performed in $0.5 \mathrm{M}$ $\mathrm{H}_{2} \mathrm{SO}_{4}$ and Ar-saturated solution.

The turnover frequency (TOF) of the synthesized materials and Ir-black can be calculated from the $\operatorname{Ir}^{\mathrm{III}} / \mathrm{Ir}^{\mathrm{IV}}$ redox peak:

$$
\mathrm{TOF}=\mathrm{j} /\left(\mathrm{z} \mathrm{N}_{\mathrm{s}} \mathrm{Q}_{\mathrm{e}}{ }^{-}\right)
$$

Where $\mathrm{j}$ is the current density, $\mathrm{Q}_{\mathrm{e}}^{-}$the electron charge and $\mathrm{N}_{\mathrm{s}}$ the number of active sites from the $\mathrm{Ir}^{\mathrm{III}} / \mathrm{Ir}^{\mathrm{IV}}$ redox peak. Figure 4 shows the obtained TOF with respect to the overpotential. As expected, Ir-black has the lowest TOF due to the high oxidation peak of $\mathrm{Ir}^{\mathrm{III}} / \mathrm{Ir}^{\mathrm{IV}}$. All the synthetized catalysts show higher TOF than Ir-black. Interestingly, the TOF of the catalyst Ir-nano 99.5 \CTAB is higher than Ir-nano 99.8 and Ir-nano 99.5, yet it is not the catalyst with the highest activity. This result means that the relationship between OER activity and the redox peak of $\operatorname{Ir}^{\mathrm{III}} / \mathrm{Ir}^{\mathrm{IV}}$ is not necessary linear, although these differences may originate due to the overlapping of the oxidation peak and capacity current. The analysis of the capacity current at potentials between $1.26 \mathrm{~V}$ and $1.3 \mathrm{~V}$, where almost no faradaic process takes place, provides a better correlation (correlation coefficient: 0.97) with the OER activities (Table 3 and Figure $4 b$ ). 

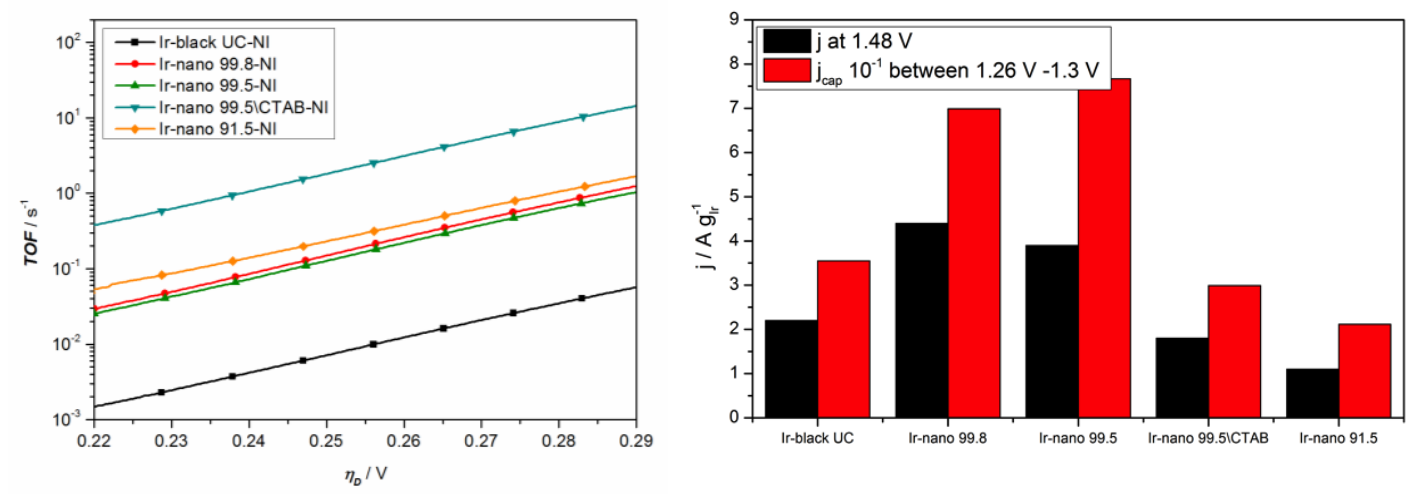

Figure 4. a) TOF of all materials. b) Comparison of the specific activation current at 1.48 $\mathrm{V}(250 \mathrm{mV}$ overpotential) and the specific average capacitive current between $1.26 \mathrm{~V}$ and $1.3 \mathrm{~V}$.

\section{Conclusions}

In this work, we investigated the impact of using ethanol of different purities and water as a solvent for the synthesis of Ir nanoparticles as OER catalyst. In addition, the effect of eliminating the stabilizing agent CTAB in the synthesis procedure was studied. In general, the decrease of solvent purity leads to a material with reduced OER activity. Moreover, the surfactant is necessary for an optimized synthesis. The small difference in the activity between of $\mathrm{EtOH} 99.5$ and $\mathrm{EtOH} 99.8$ is within the experimental error. This result is relevant for industrial applications, taking to account, that the former is twice as costly as the later solvent. No clear trend between the OER activity at specified overpotential and determined specific exchange current was found, assuming that all synthesized catalysts have similar structure and number of active sites. The discrepancy may be due to errors of iR or capacity correction for analyzing the Tafel diagrams, which resulted in changes in the slopes. The correlation between the Tafel slope and activity of materials synthetized in similar conditions is worth of further investigation as well as the use of the redox peak $\operatorname{Ir}^{\mathrm{III}} / \mathrm{Ir}^{\mathrm{IV}}$ for determining the OER active sites.

\section{Acknowledgments}

The authors acknowledge the Federal Ministry for Economic Affairs and Energy (BMWi) for financial support in the project No. 0325440A.

\section{References}

1. United Nations, Kyoto Protocol To the United Nations Framework Kyoto Protocol To the United Nations Framework; 1998; Vol. 7.

2. United Nations, ADOPTION OF THE PARIS AGREEMENT; 2015.

3. Nitsch, J.; Pregger, T.; Naegler, T.; Heide, D.; Tena, D. L. de; Trieb, F.; Scholz, Y.; Nienhaus, K.; Gerhardt, N.; Sterner, M.; Trost, T.; Oehsen, A. von; Schwinn, R.; Pape, C.; Hahn, H.; Wickert, M.; Wenzel, B. Langfristszenarien und Strategien für den 
Ausbau der erneuerbaren Energien in Deutschland bei Berücksichtigung der Entwicklung in Europa und global; 2012.

4. Friedrich, K. A. Studie über die Planung einer Demonstrationsanlage zur Wasserstoff - Kraftstoffgewinnung durch Elektrolyse mit Zwischenspeicherung in Salzkavernen unter Druck; 2015.

5. $\quad$ Vesborg, P. C. K.; Jaramillo, T. F. RSC Adv. 2012, 2 (21), 7933.

6. Lee, W. H.; Kim, H. Catal. Commun. 2011, 12 (6), 408-411.

7. Paoli, E. A.; Masini, F.; Frydendal, R.; Deiana, D.; Schlaup, C.; Malizia, M.; Hansen, T. W.; Horch, S.; Stephens, I. E. L.; Chorkendorff, I. Chem. Sci. 2015, 6 (1), 190-196.

8. $\quad$ Lettenmeier, P.; Wang, L.; Golla-Schindler, U.; Gazdzicki, P.; Cañas, N. A.; Handl, M.; Hiesgen, R.; Hosseiny, S. S.; Gago, A. S.; Friedrich, K. A. Angew. Chemie 2016, 128 (2), 752-756.

9. $\quad$ Smith, R. D. L.; Prévot, M. S.; Fagan, R. D.; Zhang, Z.; Sedach, P. A.; Siu, M. K. J.; Trudel, S.; P., B. C. Science 2013, 340 (April), 60-63.

10. Reier, T.; Pawolek, Z.; Cherevko, S.; Bruns, M.; Jones, T.; Teschner, D.; Selve, S.; Bergmann, A.; Nong, H. N.; Schlögl, R.; Mayrhofer, K. J. J.; Strasser, P. J. Am. Chem. Soc. 2015, 137 (40), 13031-13040.

11. Oh, H.-S.; Nong, H. N.; Reier, T.; Gliech, M.; Strasser, P. Chem. Sci. 2015, 00 (6), $1-8$.

12. Nong, H. N.; Oh, H.-S.; Reier, T.; Willinger, E.; Willinger, M.-G.; Petkov, V.; Teschner, D.; Strasser, P. Angew. Chemie Int. Ed. 2015, 54 (10), 2975-2979.

13. Wang, L.; Lettenmeier, P.; Golla-Schindler, U.; Gazdzicki, P.; Cañas, N. A.; Morawietz, T.; Hiesgen, R.; Hosseiny, S. S.; Gago, A. S.; Friedrich, K. A. Phys. Chem. Chem. Phys. 2015, 18, 4487.

14. Lettenmeier, P.; Wang, R.; Abouatallah, R.; Helmly, S.; Morawietz, T.; Hiesgen, R.; Kolb, S.; Burggraf, F.; Kallo, J.; Gago, A. S.; Friedrich, K. A. Electrochim. Acta 2016, $210,502-511$.

15. Nong, H. N.; Gan, L.; Willinger, E.; Teschner, D.; Strasser, P. Chem. Sci. 2014.

16. Minguzzi, A.; Lugaresi, O.; Achilli, E.; Locatelli, C.; Vertova, A.; Ghigna, P.; Rondinini, S. Chem. Sci. 2014, 5, -.

17. Damjanovic, a.; Dey, a.; Bockris, J. O. J. Electrochem. Soc. 1966, 113 (7), 739.

18. Sanchez Casalongue, H. G.; Ng, M. L.; Kaya, S.; Friebel, D.; Ogasawara, H.; Nilsson, A. Angew. Chem. Int. Ed. Engl. 2014, 53 (28), 7169-7172.

19. De Pauli, C. P.; Trasatti, S. J. Electroanal. Chem. 1995, 396 (1-2), 161-168. 
